\title{
Jornalismo 3.0: o impacto dos agregadores de notícias online no negócio da informação
}

\author{
Daniela Real Santos \\ Universidade Católica Portuguesa, Portugal \\ E-mail: dani_santos_8@hotmail.com
}

\begin{abstract}
Resumo
Nos últimos anos, o mercado da informação tem sofrido uma reconfiguração no que respeita ao modelo de negócio, ao consumo e à forma de distribuição e produção noticiosa. Estas transformações foram proporcionadas por uma convergência tecnológica marcada pela digitalização dos meios e por novas formas de disseminação dos conteúdos. O jornalismo em Portugal está perante um ambiente 3.0, marcado pela popularização da internet e dos agregadores, bem como pelo papel crucial que o cidadão comum desempenha no processo de news distributing. Este artigo pretende investigar como as mudanças em curso no mercado dos media são percecionadas pelos principais agentes envolvidos no ne-

gócio da informação, nomeadamente os media sociais, agregadores de notícias, media digitais e tradicionais. Os resultados indicam que, por um lado, os agregadores proporcionam visibilidade, angariação de novos públicos e ampliam novas formas de distribuição da informação, potenciando a marca do media e não se apropriando dela. Por outro lado, geram dependência. sendo uma desvantagem, porque os meios já não conseguem sobreviver sem o agregador, perdendo a valorização da sua marca. Cria-se uma relação de desconfiança em detrimento dos próprios media ou comprometendo o retorno dos media. Estão dependentes independentemente do retorno que obtêm dessa aliança.
\end{abstract}

Palavras-chave: agregadores de notícias; web 3.0; Portugal; jornalismo; convergência; modelos de negócio.

\begin{abstract}
In the last years, the information market has been reconfigured in terms of business model, consumption, production and circulation of news content. These changes were provided by a technological convergence marked by the digitalization of media and dissemination of contents. Today, the journalism in Portugal is facing a 3.0 environment marked by the popularization of the internet, and the crucial role

that the citizen plays in the News distributing process. The purpose of this article is to investigate how these current changes in the media market are perceived by the main agents of business information, as news aggregators, digital and outlet media. The results show that aggregators provide more visibility and attractiveness of new audiences and increase new forms of news distributing enhancing the
\end{abstract}

Data de submissão: 2017-12-16. Data de aprovação: 2018-04-26.

A Revista Estudos em Comunicação é financiada por Fundos FEDER através do Programa Operacional Factores de Competitividade - COMPETE e por Fundos Nacionais através da FCT - Fundação para a Ciência e a Tecnologia no âmbito do projeto Comunicação, Filosofia e Humanidades (LabCom.IFP) UID/CCI/00661/2013.
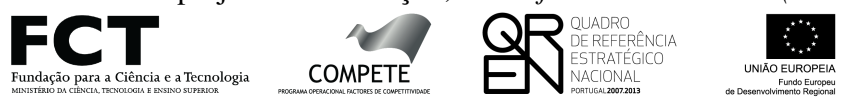

\密离




brand and not appropriating it. On the other hand, their dependence is perceived as a disadvantage because the media can no longer survive without the aggregator, losing the value of their brand. It's cre- ated a distrust relationship, to the detriment of the media themselves or by compromising the return of the media. They are dependent, independently of the return they get from this alliance.

Keywords: news aggregators; Web 3.0; Portugal; Journalism; convergence; business models.

\title{
INTRODUÇÃO
}

\begin{abstract}
A TUALMENTE, grande parte da população do mundo ocidental consome diariamente variados conteúdos através da internet. Com a crescente afirmação da internet, novos agentes começam a surgir e a vingar no jornalismo, ganhando enorme importância junto da audiência. Pelo facto de o consumo se processar maioritariamente através dos novos agentes, os media sentiram necessidade de reestruturar modelos de negócio, de consumo e de distribuição da informação, bem como as relações entre os media. Todas estas mudanças em curso fazem parte de um processo de remediation (Bolter e Grusin, 1999), que se enquadra no jornalismo 3.0 e do qual fazem parte os agregadores de notícias online. Segundo Piet Bakker (2012), o jornalismo 3.0 é um jornalismo participativo, de cidadão, ou seja, a terceira versão do jornalismo digital. Cronologicamente, o jornalismo 1.0 é aquele que transmite conteúdo tradicional de meios analógicos para o ciberespaço. O jornalismo 2.0 é a criação de conteúdo de e para a rede, e por fim o jornalismo 3.0 socializa esses conteúdos e os próprios meios. A entrada destes novos agentes no mercado das notícias, e as consequências que daí advêm levam a que esta seja uma problemática atual e fundamental de se estudar, pelas sérias mudanças que está a produzir no negócio da informação.

Os agregadores de notícias online podem ser definidos como sites de notícias que se dedicam a republicar e a fazer curadoria das notícias de outros media no seu próprio site, ou seja, fazem todo um processo de pós-produção, através de contratos legais de parceria. Na sua grande maioria, não produzem conteúdo original. Os agregadores são uma tendência relativamente recente em Portugal, emergente do jornalismo 3.0.

Este artigo centra-se na análise dos agregadores de notícias online pelo seu papel fundamental no negócio do jornalismo, nomeadamente na distribuição e no consumo de informação. Face ao seu inevitável crescimento, é importante investigar de que modo é que os vários stakeholders do negócio da informação percecionam as mudanças em curso no jornalismo, particularizando o papel dos agregadores, a reconfiguração do negócio da informação, o potenciar do jornalismo 3.0, bem como, e de que forma, influenciam a produção noticiosa. Escolhemos variados grupos de stakeholders para compor este estudo: os jornalistas, diretores dos media tradicionais, editores online, media sociais, media híbridos, grupos de media que romperam contrato com agregadores, grupos de media que não aderiram aos agregadores e grupos de media que aderiram aos agregadores. Para este artigo considerámos também três agregadores de notícias online em Portugal, que mais tarde entrevistámos: MSN Notícias, Google News e o Sapo.pt. A escolha de todos estes stakeholders devem-se à forma muito diferente de gestão e de negócio entre si, e demonstram muito bem a realidade dos agregadores que dominam o mercado.
\end{abstract}


Neste artigo considerámos também duas importantes linhas condutoras: a gestão e produção noticiosa e o consumo, de forma a conseguir responder à questão de investigação, que visa saber qual o impacto dos agregadores de notícias no jornalismo em Portugal. Para isso foi necessário elencar mais três subquestões a este estudo: 1) qual a relação entre os media tradicionais e os novos meios de comunicação online, os agregadores? 2) quais as transformações que ocorrem em termos de padrões de consumo de notícias devido ao surgimento dos agregadores? 3) quais os principais desafios e mudanças que surgiram em termos de produção noticiosa na atividade jornalística?

Este estudo exploratório contribuirá, assim, para desbravar um território de investigação novo em Portugal e que já está a produzir sérios efeitos no mercado dos media nacionais.

$\mathrm{O}$ artigo começa por analisar a convergência e transmediação dos media no mercado da informação, bem como a adaptação dos mesmos aos novos agentes do jornalismo 3.0, nomeadamente os agregadores de notícias, media sociais e digitais. Depois apresentamos a metodologia de investigação usada neste artigo, a que se segue a análise dos dados, que inclui a triangulação e comparação de fontes, teorias, tendências e métodos. Por fim, retiramos um conjunto de ilações sobre o impacto dos novos agentes no negócio da informação.

\section{A CONVERGÊNCIA DOS media NO MERCADO DA INFORMAÇÃo}

Atualmente vivemos numa era marcada pelos efeitos da convergência (Foust, 2005:247), que é um conceito que descreve as mudanças tecnológicas, culturais, industriais e sociais no mercado da informação, e também a transmediação dos media, que compreendem uma constante digitalização e disseminação dos meios. A digitalização veio potenciar o crescimento de plataformas, fomentando a disseminação de notícias e de informação das mais variadas fontes a um ritmo cada vez mais acelerado. Jenkins, Ford e Joshua (2013) definiram estas alterações com um modelo que designaram por spreadability model, que caracteriza muito bem o atual crescimento de um modelo híbrido de circulação de informação entre os media e também entre agregadores de notícias. Spredeability refere-se à capacidade de as audiências partilharem conteúdo com um propósito próprio, tornando o cidadão comum muito mais ativo e participativo. As variadas plataformas e canais de consumo existentes levaram a uma inevitável fragmentação das audiências, como consequência de um consumo cada vez mais individualizado.

Os agregadores de notícias online são vistos como espaços de convergência, como o caso do MSN, Sapo e Google, pois funcionam como processadores de notícias e organizadores de conteúdo noticioso, disponibilizando os conteúdos que vêm de outras fontes. Os media sociais são também espaços de convergência, pois promovem o comentário e a partilha do cidadão comum, em que o user passa a ser simultaneamente produtor e consumidor. Todos estes processos fazem parte de uma era do liquid journalism, termo cunhado por Mark Deuze (2008), em que a identidade do jornalismo é vista como liquida, isto é, um jornalismo que vive ao serviço da sociedade em rede que temos hoje.

Os novos agentes, tais como os agregadores de notícias, os portais, os motores de busca emergiram destes dois fenómenos atrás mencionados: a digitalização e a transmediação. O próprio modelo de negócio é afetado por estes movimentos de convergência. Um dos eixos de análise 
deste artigo trata precisamente do modelo de negócio. A viragem dos interesses para a indústria do entretenimento e a aposta nos comerciais e publicidade no online, levou a um declínio do papel e dos próprios leitores. A depreciação do atual modelo de negócio, em conjunto com o aumento das pressões comerciais, desvaloriza o jornalismo, o interesse público, dificulta a captação de notícias, o trabalho de campo, a reportagem de investigação e as notícias locais (Fenton, 2010). Porque nada destas tarefas jornalísticas contribui para as economias de escala que as empresas procuram. É o modelo de negócio que dita a política de um medium. A forma como se posiciona no mercado define a sua estratégia de concorrência e o seu posicionamento face aos outros players (Athey e Mobius, 2012).

O negócio dos agregadores nasce como algo inovador num mercado tradicional dos media, mercado esse fortemente dependente de publicidade e de vendas em papel. As mudanças que o digital trouxe não conseguiram acompanhar as anteriores receitas do tradicional, por isso os media estão atualmente a passar por uma fase de crise económica e de reestruturação do modelo de negócio. É cada vez mais difícil monetizar conteúdos num espaço onde tudo é gratuito. No entanto, é nas audiências que se exploram novos modelos de negócio e se sofisticam os atuais. Os padrões de consumo ditam as regras de gestão de negócio de um medium, pelo que se torna importante cada meio definir a sua própria audiência (Bakker, 2012).

Embora a televisão ainda continue a ser um meio privilegiado de obtenção de informação, segundo um estudo recente da ERC (2015), os motores de busca, agregadores de notícias e apps têm vindo a crescer exponencialmente. Por isso é fundamental perceber e investigar de que forma estes novos agentes têm vindo a impactar o jornalismo.

A multiplicidade de plataformas, rapidez e instantaneidade da informação e do consumo potenciam a fragmentação das audiências. As transformações da audiência devem-se, em grande parte, a um público cada vez mais ativo e participante no processo de produção e consumo de informação. Dessa forma, a progressiva comercialização dos meios de comunicação veio potenciar uma cultura do entretenimento, construindo uma relação emocional e de proximidade com a audiência, concedendo-lhe o papel principal. Esta demotic turn, termo cunhado por Turner (2010), evidencia muito bem a democratização do acesso e a viragem dos interesses dos media para uma cultura popular assente na tabloidização. As audiências tornam-se assim mais específicas, personalizadas e cada vez mais exigentes, a necessidade de saber o que se passa ao segundo é enorme. A longo prazo, as notícias terão uma perspetiva mais virada para o entretenimento, com o objetivo de satisfazer aqueles que pretendem distração. No entanto, apostar exclusivamente em notícias leves pode levar a que os interessados em notícias sérias percam o gosto de seguir tal meio. Este tipo de leitores, telespectadores e ouvintes são irrecuperáveis. Criar ou perder hábitos de consumo podem levar anos, mas uma vez perdidos não se recuperam facilmente.

Holton (2010) refere que atualmente a sociedade se encontra no quinto estágio de fragmentação das audiências, intitulada "convergência da fragmentação". É caracterizado pela existência de small worlds, que são esferas de indivíduos ligados pelos mesmos mecanismos, formando uma rede de comunicação. São pessoas que aderiram ao mesmo meio, as chamadas redes sociais. Estas funcionam como ferramentas úteis para o media chegar a outros públicos. Com a entrada de novos players a fragmentação é cada vez mais acentuada, devido à repartição de audiências e do investimento, sobretudo no online. $\mathrm{O}$ aumento de plataformas pode significar mais oferta $\mathrm{e}$ 
mais informação, mas ao mesmo tempo significa descentralização do consumo e gera uma forte competitividade entre os media.

Os agregadores de notícias vieram ampliar as formas de distribuição das notícias, dando a possibilidade de condensar toda a informação numa única plataforma. No entanto, os restantes media estão ainda muito dependentes de rotinas jornalísticas cada vez mais estandardizadas e padronizadas nas redações. Mark Deuze (cit in Lance Bennet, 2007) refere que o jornalista está subjugado por pressões, normas e convenções e por uma forte dependência face aos "canais de rotina" e pelos novos agentes que funcionam como geradores de opinião e de conteúdo.

O jornalista encontra-se num processo de gatewatching (Patterson et al., 2008) em que observa as várias fontes de informação e faz um filtro daquilo que encontra, identificando o que é importante e relevante, bem como de interesse público para toda a comunidade. O exercício da profissão encontra-se também numa fase marcada por uma nova sociologia da produção, assinalada pela omnipresença e contemporaneidade, onde a individualização, a globalização e o papel das novas tecnologias em rede desafiam todos os pressupostos tradicionais. As rotinas do jornalismo alteraram-se, seja num agregador ou num meio tradicional, e baseiam-se muito na curadoria da informação e na decisão, isto é, segmentar, selecionar e filtrar o conteúdo para cada público-alvo (Guerrini, 2013).

A relação entre os agregadores e os media é pouco clara e está longe de ser consensual. Alguns meios apontam vantagens e algumas desvantagens no uso de agregadores, não havendo um consenso de opiniões. Rupert Murdoch, por exemplo, tem uma perspetiva negativa relativamente aos agregadores, chegando mesmo a referir que "produzir jornalismo é caro. Nós investimos imensos recursos desde a tecnologia até aos nossos salários. Agregar histórias não é justo. É um "roubo" (Lee e Chyi, 2015:4 ${ }^{1}$ ).

Nos Estados Unidos da América, o surgimento dos agregadores de notícias começou mais cedo do que no resto do mundo. Grande parte dos confrontos anteriores deviam-se à agregação que o Google fazia do conteúdo de outros media. Na altura, levantaram-se várias questões legais de copyright e relativas ao direito do Google sobre republicação de conteúdos (Athey e Mobius, 2012). No início, quando estes sites agregadores começaram a emergir, a prática de agregação de conteúdos digitais num único site de notícias levou a processos judiciais e a incertezas sobre as consequências económicas destas práticas. Na altura, defendia-se, por um lado, que os agregadores poderiam funcionar como um complemento, na medida em que dão tráfego e visibilidade, ou até mesmo um substituto das fontes de notícias originais, levando os utilizadores a migrar para outros meios e plataformas. Era um caos, porque as empresas de media estavam desconfiadas se seria rentável e legal este tipo de modelo de negócio.

Desta forma, esta relação pode ser descrita por uma dependência mútua não desejada por ambas as partes. Os agregadores precisam dos produtores de notícias, porque vivem deles para garantir a sua sobrevivência online; e os media precisam dos agregadores para conseguirem chegar a mais públicos. Dessa forma, é uma relação simbiótica, pois ambos saem beneficiados. No fundo, os meios de comunicação estão a adaptar-se às novas realidades trazidas pelo jornalismo

1. Tradução de: "Producing journalism is expensive. We invest tremendous resources in our project from technology to our salaries. To aggregate stories is not fair use. To be impolite, it is theft" (p.4). 
3.0. Essa mesma competitividade existente entre os novos agentes e os media é medida através do investimento publicitário e da captação de audiências.

Face a este enquadramento, a partir da perceção dos vários stakeholders envolvidos no negócio da informação, o estudo que aqui se apresenta pretende aferir o tipo de relação entre os vários stakeholders envolvidos no negócio da informação na era do jornalismo 3.0. Para tal, apresentamos de seguida o desenho metodológico deste estudo exploratório.

\section{METODOLOGIA}

Tal como já referido, neste estudo pretendemos analisar o impacto dos agregadores de notícias online no jornalismo em Portugal, no que respeita à audiência e às mudanças na produção e gestão noticiosa a partir da perspetiva dos players do negócio.

Esta é uma investigação de natureza exploratória, onde optámos pelo recurso a entrevistas em profundidade, tendo feito posteriormente uma análise categorial temática. Optámos por este método, pois pretendemos analisar várias questões e fenómenos de carácter social, o que dificilmente poderia ser feito com um estudo quantitativo. O objetivo passa por descrever um meio social e os seus componentes, neste caso, os agregadores.

É de natureza exploratória porque investiga uma problemática pouco estudada em Portugal em termos académicos. Pretende desbravar um território novo, mas que já produziu sérios efeitos para as mudanças em curso no mercado das notícias. Ao ser exploratório, torna-se importante recolher o máximo de informação possível, através do recurso a entrevistas em profundidade. $\mathrm{O}$ foco das entrevistas são os protagonistas escolhidos. Através desta técnica, pretende-se analisar as dinâmicas de mudança, se existem resistências, receios e expectativas por parte dos principais stakeholders.

As entrevistas foram semiestruturadas, por pauta, dividida por diferentes blocos de análise: produção noticiosa, modelo de negócio, consumo e relação entre os media. Todos os entrevistados responderam a quatro blocos, excepto os jornalistas e editores que não responderam às questões sobre o modelo de negócio. Foram criados dez guiões de entrevistas para dezanove entrevistados. As questões foram abertas e pouco diretas, de forma a deixar o entrevistado falar livremente. São entrevistas centradas com o objetivo de estudar algo específico e tiveram uma duração média de quarenta minutos.

O tratamento das entrevistas teve por base uma análise categorial temática, em que se visa estabelecer uma categorização das várias partes do texto e das entrevistas, sendo esta uma forma mais prática e simplificada de análise. A escolha destas quatro categorias teve em conta tudo o que foi abordado neste estudo, de forma a conseguir responder às questões de investigação.

Os stakeholders são específicos, pois cada entrevistado não pode ser substituído ou retirado, se não estaria a prejudicar a validade da investigação. Todos os entrevistados têm uma relação entre si. Estes indivíduos foram escolhidos estrategicamente pelo lugar que ocupam na dinâmica desta relação. A amostra foi constitída em função das características precisas que pretendem ser analisadas. O objetivo é estudar como cada stakeholder perceciona, a partir do seu lugar, e como estas perceções se compatibilizam ou não. Foram escolhidos principalmente diretores e entrevistados com um cargo de importância num grupo de comunicação e ao mesmo tempo ligados às áreas em 
estudo. Este trabalho englobou assim vários grupos de stakeholders: jornalistas, editores do MSN, Google e Sapo, diretores de media tradicionais e de agregadores de notícias, responsáveis por grupos de media que aderiram aos agregadores, responsáveis por grupos de media que não aderiram e representantes de meios que romperam contrato com os agregadores, media híbridos (são meios de comunicação que reunem simultaneamente as características de um agregador de notícias, bem como de um meio tradicional) e coordenadores de media sociais. Entrevistámos dois jornalistas seniores, visto que ambos presenciaram as grandes transformações do tradicional para o online e agora assistem às novas tendências emergentes. Entrevistámos também um jornalista com menos anos de profissão, mas que nos dá uma dupla visão de quem já trabalhou num agregador, e de quem atualmente trabalha num meio de comunicação simultaneamente digital e tradicional, a revista Sábado. No grupo dos editores não incluímos o Google, porque não tem editores humanos, uma vez que tudo é programado por algoritmos. No grupo dos diretores dos meios tradicionais foram feitas entrevistas englobando três meios tradicionais: imprensa (Público), Rádio (R/Com) e TV $(R T P)$, para nos dar uma perspetiva diferenciada e mais rica do modelo de negócio, consumo e produção noticiosa dos media. O grupo dos diretores dos agregadores de notícias foi constituído pelos três agregadores em estudo: MSN, Google e Sapo, de forma a perspetivar a forma como os agregadores se têm vindo a posicionar e a crescer no mercado português.

De seguida, temos o bloco de entrevistados que aderiram, que não aderiram e que romperam contrato com agregadores. Este grupo de entrevistados proporciona uma visão comparativa do trabalho entre meios e agregadores e também porque são atores que participam ativamente neste fenómeno dos agregadores, e que lidam diariamente com tal realidade. Os meios híbridos que incluem o Observador e o Expresso, não são agregadores nem o foco do estudo, mas são modalidades híbridas que contêm características de um agregador e de um media tradicional, e começam a surgir e a vingar pela primeira vez em Portugal. Daí que considerámos adicionar à investigação fenómenos adicionais inseridos no jornalismo 3.0 e que nos ajudam a perspetivar as mudanças no jornalismo, dando assim mais valor à investigação. Por fim, e não menos importante, incluímos o grupo dos media sociais constituído pelo Facebook, por ter mais influência em Portugal comparativamente com o Twitter ou o Instagram. O Facebook é também um agregador puro (Patterson, 2008), ou seja, um feed aggregator - um website que contém uma grande quantidade de outros websites e media tradicionais que são organizados por diferentes fontes, tópicos ou história - embora com modelos de negócio muito diferentes dos restantes agregadores de notícias. Numa era cada vez mais marcada pelo consumo de notícias nos media sociais, é importante entrevistar o representante do Facebook em Portugal, nomeadamente para obtenção de dados sobre audiências, bem como informação sobre o modelo de negócio assente neste tipo de redes.

Depois de realizar as entrevistas, foi necessário fazer o seu tratamento. Para tal, foram estabelecidos quatro quadros de análise: o primeiro tratou de atribuir uma letra a cada entrevistado. De seguida, foi feito um segundo quadro com o fim de tratar a informação para cada entrevistado de acordo com as quatro temáticas de análise. Depois foi feito um terceiro quadro, elencando tudo aquilo que os entrevistados disseram sobre cada categoria. Por último estabeleceu-se um quadro divisório por cada conjunto de stakeholders, condensando tudo o que disseram sobre determinado tema no seu respetivo grupo. A análise do texto das entrevistas foi também dividida em três aspetos: vantagens, desvantagens e possíveis desafios por cada categoria de análise. Para além disso, 
também se agruparam os grupos de stakeholders, ou seja, todos os entrevistados foram reinseridos, cada um deles em dois grandes grupos: o grupo dos media tradicionais, constituído pelos jornalistas, diretores dos media tradicionais; e o grupo dos agregadores de notícias, constituído pelos editores, diretores dos agregadores de notícias, os media que romperam, aderiram, e que não aderiram aos agregadores, media híbridos e ainda os media sociais.

As entrevistas foram trabalhadas tendo por base uma análise categorial temática, abordando as grandes quatro dimensões da investigação. "O objetivo é estabelecer uma correspondência entre o nível empírico e teórico, de modo assegurar-nos - e esta é a finalidade de qualquer investigação que o corpo de hipótese é verificado pelos dados do texto" (Bardin, 1977:69).

Um dos pontos que Laurence Bardin estabelece na análise de conteúdo é o cruzamento entre a resposta e a pergunta, ou seja, se existe aceitação ou recusa por parte do entrevistado face à temática. Neste caso, como foi referenciado anteriormente, foram elencados os pontos favoráveis (aceitação) e desfavoráveis (recusa) de cada temática. Ainda nesta fase foram extraídas as variações internas dentro de cada grupo de stakeholders (medias tradicionais e agregadores) sobre as suas posições face às categorias. O objetivo passa por verificar se existe um consenso de opiniões e teorias ou se, contrariamente, existe uma polaridade dentro de cada grupo.

Por último, foram condensadas todas as fases anteriores num quadro, onde reunimos os conceitos/palavras-chave divididas pelas quatro categorias estudadas. Importa referir que estas duas posições, favorável e desfavorável, não se definem por oposição de cada posição identificada. Dessa forma, através da perceção dos stakeholders entrevistados, pretendeu-se aferir a influência dos agregadores de notícias no mercado da informação. Para isso foi necessário interpretar e condensar toda a informação relativa ao modelo de negócio, consumo, produção noticiosa e relação entre os media, dada pelos principais protagonistas que lidam diariamente com estas problemáticas atuais, análise debatida na próxima secção deste artigo.

\section{A INFLUÊNCIA DOS AGREGADORES DE NOTÍCIAS NO MERCADO DA INFORMAÇÃO}

As entrevistas foram feitas aos atores de cada grupo de stakeholders para apreender a perspetiva desse grupo a partir do seu ponto de interesse na questão dos agregadores.

Tendo em conta o panorama digital e transmediático, o receio e a desconfiança face aos novos players é crescente. Optar por aderir às novas tendências e adaptar-se aos novos players torna-se inevitável, quando falamos de um mercado que se está constantemente a reinventar. Se o media não se adaptar acabar por se perder e ficar "para trás", ameaçando a sua sobrevivência num mercado onde existe sobreabundância de oferta.

O surgimento dos agregadores de notícias e a afirmação crescente dos media sociais devem-se ao constante avanço tecnológico e à reinvenção do próprio jornalismo, que passa a estar numa era designada por jornalismo 3.0.

Uma das subquestões deste estudo trata de investigar quais são os principais desafios e mudanças que surgiram em termos de produção noticiosa na atividade jornalística em Portugal (tabela 1). Para conseguir responder a esta subquestão, foi necessário incluir a categoria da produção noticiosa na análise, considerando sempre as perspetivas dos dois grupos de stakeholders: agrega- 
dores de notícias e media tradicionais. As perceções dos entrevistados foram divididas por posição favorável e posição desfavorável, como se pode ver de seguida nas tabelas de análise.

Tabela 1. A perceção dos stakeholders face à produção e gestão noticiosa

\begin{tabular}{|c|c|}
\hline Posição favorável & Posição desfavorável \\
\hline $\begin{array}{l}\text { Facilidade, utilidade, comodidade na busca de in- } \\
\text { formação e aumento da capacidade de pesquisa }\end{array}$ & Jornalismo de secretária \\
\hline Rapidez e instantaneidade da informação & Repetição de notícias \\
\hline Emoção e insólito como valores-notícia & Dependência dos media e das plataformas \\
\hline Vasta hipótese de recolha & O jornalista como megafone de outras fontes \\
\hline $\begin{array}{l}\text { Concentração da informação numa única plata- } \\
\text { forma, banca de jornais }\end{array}$ & $\begin{array}{l}\text { Perda de credibilidade e falta de identificação da } \\
\text { fonte }\end{array}$ \\
\hline $\begin{array}{l}\text { Aumento da visibilidade dos media com a ampli- } \\
\text { ação e distribuição dos seus conteúdos }\end{array}$ & Afirmação do jornalista-cidadão-amador \\
\hline Verificação do conteúdo & Imediatismo e rapidez nos valores-notícia \\
\hline Gatekeeping e Gatewatching & $\begin{array}{l}\text { Newsrooms digitais, mais pequenas e sem memó- } \\
\text { ria }\end{array}$ \\
\hline Fundição do jornalista e do web editor & Agregadores como mosaicos de notícias \\
\hline Mix de agendas dos media & Falta de um público específico \\
\hline Media sociais como geradores de opinião & Afirmação do jornalista cidadão amador \\
\hline Fidelização do consumidor & Desbaratamento das próprias marcas \\
\hline $\begin{array}{l}\text { Aumento das competências tecnológicas e rees- } \\
\text { truturação das capacidades do jornalista }\end{array}$ & $\begin{array}{l}\text { A notícia baseada nos media sociais, vistos como } \\
\text { fontes de informação }\end{array}$ \\
\hline \multirow[t]{4}{*}{ Relevância e interesse público } & Desculturação da sociedade \\
\hline & $\begin{array}{l}\text { Informação menos sofisticada e mais "faceboo- } \\
\text { kada" }\end{array}$ \\
\hline & $\begin{array}{l}\text { Valor-audiência, determinado pelo clique byte, fá- } \\
\text { cil e rápido }\end{array}$ \\
\hline & Os instant articles do Facebook \\
\hline \multicolumn{2}{|c|}{ Possíveis problemas/Desafios } \\
\hline Futuro pouco agradável para o jornalismo & $\begin{array}{l}\text { Aumento de produção dos conteúdos } 360^{\circ} \text { para } \\
\text { várias plataformas }\end{array}$ \\
\hline Degradação da qualidade do jornalismo & $\begin{array}{l}\text { Equilíbrio e sustentabilidade entre agregadores e } \\
\text { media }\end{array}$ \\
\hline
\end{tabular}

Tendo em conta a análise das entrevistas, entende-se como tendo posição favorável todos os entrevistados que vêm aspetos positivos nos agregadores de notícias em termos de produção e gestão noticiosa, consumo, modelo de negócio e relação entre os media, como por exemplo:

"O público do agregador é mais democrático, é uma representação muito variada do que é a população. É um público que não vem à procura, não é exigente, cai na página e algum conteúdo o agarra. A nossa função é fazer com que as pessoas que caiam fiquem na nossa página." (Editora chefe do $M S N$, grupo dos agregadores de notícias). 
Contrariamente, entende-se por posição desfavorável todas aquelas perceções que tenham aspetos negativos sobre os agregadores de notícias face aos media, como por exemplo:

\footnotetext{
"Os órgãos de informação produzem exclusivamente para as redes sociais, acabando o próprio público de migrar de agregadores e meios de comunicação para media sociais. Isto só mostra que a exigência de informação tem diminuído, apesar de as possibilidades serem exponenciais. Os agregadores fomentam esta passividade e menor exigência." (Jornalista sénior e professor, grupo dos media tradicionais).
}

Dessa forma, verifica-se que não existe polaridade de opiniões no grupo dos media tradicionais, em termos da categoria da produção noticiosa. Os agregadores são vistos como plataformas de distribuição e ampliação da informação e não como produtores de notícias, ou seja, são equiparados a uma banca de jornais. A notícia é determinada cada vez mais pela audiência do que pela agenda dos media, ou seja, tudo o que se torna viral e gere buzz torna-se um acontecimento noticiável. A notícia é baseada nos interesses da audiência e não naquilo que a audiência deve consumir, daí que o valor-audiência se sobreponha ao valor-notícia nas redações. Ao mesmo tempo verifica-se cada vez mais uma escassez do trabalho de campo, uma repetição constante das notícias (Lopes, 2015), uma perda de credibilidade e por consequência, a informação torna-se menos sofisticada e mais centrada naquilo que o Facebook e as restantes redes sociais dizem. A isto chama-se "jornalismo de secretária", isto é, fazer jornalismo sem sair da redação, copiando e estando dependente das notícias dos outros. As newsrooms são cada vez mais digitais e pequenas, tendo sempre presente o imediatismo e a rapidez como valores-notícia.

Algumas opiniões divergiram tanto no grupo dos media tradicionais como no dos agregadores de notícias. Vários entrevistados consideraram que houve uma reestruturação do jornalista, enquanto outros alegam que se deu uma reestruturação das capacidades do jornalista. Este passa agora a desenvolver tarefas que antigamente não eram abrangidas na profissão. O jornalista passa de um gatekeeping para um gatewatching, na medida em que tem de observar e selecionar as várias fontes. $\mathrm{O}$ trabalho do jornalista baseia-se muito em filtrar e observar as várias gates e aquilo que pode ou não ser noticiável, tendo em conta a sobreabundância de informação. O jornalista muitas vezes funciona como um megafone de outras fontes.

Outra das opiniões prende-se com o conceito de notícia. Alguns entrevistados alegam que o conceito de notícia se alterou. No entanto, o que se observa, segundo a maioria dos entrevistados, é que as alterações se verificam ao nível da distribuição das notícias e não do conceito. Esse sim, foi alterado por questões culturais, comerciais e sociológicas, e não pelos agregadores. Por um lado, aos jornalistas é-lhes pedida uma maior exigência e rigor na recolha, tratamento e verificação das notícias, mas ao mesmo tempo a informação é cada vez menos sofisticada, isto porque os media competem com os outros media e demonstram uma forte dependência das agências de notícias e dos meios concorrentes, para saberem o que escrever e destacar nos seus suportes e plataformas.

O grupo dos agregadores de notícias reitera que estes têm como objetivo dar visibilidade ao bom trabalho feito pelos media, melhorando a experiência do utilizador. No entanto, alguns grupos de media que romperam contrato com agregadores alegam que querem evitar o desbaratamento das suas marcas ao oferecerem todos os seus conteúdos aos agregadores. Essa visibilidade tornase assim limitada. O medo, a falta de visão e a falsa sensação de controlo levam à desconfiança 
dos media face aos agregadores, e também faz com que alguns media restrinjam a utilização do seu conteúdo.

Um editor de um agregador é um curador, é o responsável por fazer todo aquele trabalho de pós-produção, de gerir e selecionar as notícias que lhe parecem mais adequadas ao interesse da audiência, bem como adaptar os conteúdos recebidos ao digital e ao tipo de público do agregador. O jornalista é o produtor puro de conteúdos. Com as constantes alterações, verifica-se uma fundição de ambas as profissões, deixando de haver uma distinção tão vincada entre agregadores e os restantes media. Alguns entrevistados incluem ambos no mesmo bolo, mostrando-se unicamente contra os media sociais, alegando que o receio dos media tradicionais não devem ser os agregadores, pois neste momento estamos numa fase em que agregadores e media se devem aliar contra os media sociais, e não o contrário.

Embora existam algumas disparidades de perspetivas entre entrevistados do mesmo grupo, são mais os pontos de concordância do que de discordância. Pode-se concluir que, para os media tradicionais, os agregadores são plataformas de distribuição que fornecem uma oferta empacotada das notícias. A facilidade, a falta de tempo e o comodismo levam a que as pessoas prefiram os agregadores. Os agregadores têm uma ideia muito próxima dos gostos da audiência devido às ferramentas de medição que usam. Por isso, o agregador funciona como um ponto de entrada para muitos leitores.

Um dos grupos de stakeholders deste estudo são os media híbridos. Não são o foco do nosso estudo, mas são meios que refletem muito bem a realidade 3.0 por que estamos a passar. Os media híbridos reúnem tanto as características de um agregador como de um media tradicional, daí que seja difícil agrupá-los isoladamente. Recentemente, o Expresso tem apostado em criar mais plataformas dentro da rede. O objetivo é conseguir desmultiplicar dentro das suas plataformas os vários assuntos e temáticas do dia, sem ter de promover as notícias no agregador. Ou seja, captar o utilizador através da própria marca e não através do recurso a outras. São novas estratégias que permitem, em certa medida, contrariar o uso dos agregadores e diminuir a sua dependência.

Para concluir a análise desta categoria de estudo, ambos os grupos de stakeholders predizem um futuro desagradável para o jornalismo, marcado por uma degradação dos critérios de noticiabilidade. Ao mesmo tempo, vai verificar-se cada vez mais a produção de conteúdos $360^{\circ}$, isto é, conteúdos para serem distribuídos em várias plataformas e suportes. 
Tabela 2. A perceção dos stakeholders face ao consumo

\begin{tabular}{|c|c|}
\hline Posição favorável & Posição desfavorável \\
\hline Condensação da informação & Passividade e menor exigência do público \\
\hline $\begin{array}{l}\text { Agregadores são o ponto de partida, são uma } \\
\text { shopstop }\end{array}$ & $\begin{array}{l}\text { Migração dos users para os agregadores e media } \\
\text { sociais, que são apanhados na rede, não procuram } \\
\text { notícias }\end{array}$ \\
\hline Interatividade e participação nas redes sociais & Crescimento do speed reading \\
\hline Democratização do acesso & Competição de todos pela atenção do público \\
\hline Agregadores e media são vasos comunicantes & $\begin{array}{l}\text { Procura do infotainment e pouco critério na diges- } \\
\text { tão das notícias }\end{array}$ \\
\hline $\begin{array}{l}\text { Não existe uma apropriação por parte dos agrega- } \\
\text { dores face à audiência }\end{array}$ & Descentralização e repartição do consumo \\
\hline $\begin{array}{l}\text { Criação do hábito de ir primeiro ao agregador ou } \\
\text { motor de busca }\end{array}$ & Pilhagem de conteúdos dos produtores \\
\hline Infotainment na base dos agregadores & $\begin{array}{l}\text { Procura de macroinformação numa lógica de con- } \\
\text { sumo diagonal }\end{array}$ \\
\hline \multirow[t]{5}{*}{ Potenciadores do bom trabalho dos media } & A importância do algoritmo para o público \\
\hline & Falta de controlo do conteúdo \\
\hline & Fragmentação das audiências \\
\hline & $\begin{array}{l}\text { Não procuram conteúdo específico nos agregado- } \\
\text { res }\end{array}$ \\
\hline & Perda de força do tradicional face ao gratuito \\
\hline
\end{tabular}

Desafios

Tem de haver abertura de ambas as partes para Caminhar para um modelo de negócio favorável criar sinergias

A segunda categoria de análise é o consumo (tabela 2). Os entrevistados apontaram algumas razões para o consumo de agregadores. Estes novos media trouxeram facilidade, utilidade e comodidade na busca de informação, aumentando as capacidades de pesquisa dos utilizadores. As pessoas que consomem agregadores contentam-se com a sua oferta empacotada das notícias, ou seja, querem apenas saber as cinco notícias do dia, numa lógica de consumo diagonal com pouco critério na "digestão" das notícias. O facto de os agregadores condensarem as marcas e temáticas numa única plataforma fomenta a passividade e menor exigência do consumidor. São sobretudo utilizadores "apanhados na rede", na maioria das vezes não vão em busca de algo, são apanhados pelo agregador através de ferramentas internas (Outlook, Skype etc.) e por alguma razão ficam e consomem na plataforma. $\mathrm{O}$ trabalho do agregador é conseguir a fidelização do consumidor, uma vez que o utilizador parou no site, que consuma e que volte lá.

"O público do agregador é mais democrático é uma representação muito variada do que é a população. É um público que não vem a procura, não é exigente, cai na pagina e algum conteúdo o agarra. A nossa função é que as pessoas que caiam fiquem na nossa página." (Editora chefe do $M S N$, grupo dos agregadores de notícias). 
O consumo no Google é diferente, embora seja também um agregador: é voluntário e pensado. As pessoas vão ao Google porque realmente querem saber e pesquisar sobre determinado assunto, que acaba por redirecionar o utilizador para o Google news. Muitas das pessoas consomem agregadores também pelo hábito. Tanto o Sapo, como o MSN e o Google são marcas muito fortes que acompanham a rotina dos utilizadores, desenvolvendo hábitos de consumo que já estão enraizados há muitos anos. O agregador funciona na maioria das vezes como o ponto de partida para o conhecimento das notícias, tendo a capacidade de condensar tudo numa única plataforma.

"Consumimos a informação na mesma medida em que consumimos num conjunto de lojas.

Nós vamos consoante nos dá mais jeito e não porque a marca está em tal sítio. Eu não menos-

prezo uma marca porque ela está no agregador, eu uso consoante me seja mais conveniente e consoante o tempo." (Diretora do Sapo, grupo dos agregadores de notícias).

Segundo Lee e Chyi (2015), motivações de informação, entretenimento e sociais vieram influenciar o consumo de notícias em termos de tempo despendido e na escolha dos conteúdos. De igual forma, os entrevistados também apontaram estes fatores como sendo os principais estimuladores do consumo.

"Motivações informacionais: saber o que se está a passar no mundo; motivações de entretenimento: é um hábito, e não há nada melhor para fazer; motivações sociais: manter-se a par do que as pessoas à sua volta estão a falar, fazer parte da comunidade e ter algum assunto para falar com os outros; motivações de opinião: ajudar a formar as suas opiniões sobre várias temáticas e expor-se tentando entender os pontos de vista diferentes do seu" (Lee e Chyi, 2015:12, tradução nossa $^{2}$ ).

Hoje, todos nós consumimos um pouco de tudo e de vários meios e marcas. A diferença entre hard e soft news (Prior, 2005) esbate-se cada vez mais. Hoje, fala-se de infotainment, em que tudo é informação, mas contada de uma forma diferente. O facto de alguns media estarem a virar os seus interesses para conteúdos de lifestyle, numa linha de soft news, não é culpa dos agregadores, mas sim do panorama cultural em que vive a sociedade. O que se verifica é o consumo de um medium em detrimento de outro medium. No entanto, isso é uma situação normal quando falamos de um mercado extremamente competitivo e com bastante oferta.

$\mathrm{O}$ aumento das plataformas de media traduz-se na repartição do consumo e na sua descentralização, pelo que a audiência tem tendência a fragmentar-se cada vez mais. A democratização do acesso também veio potenciar a participação ativa do utilizador nos processos de news making e news distributing, tendo um papel simultâneo de consumidor e produtor. Desta forma, todos os media competem pela atenção do público e pelo investimento. O consumo dos agregadores e dos media sociais prevalece, pela pouca exigência dos consumidores, falta de tempo e rapidez. Os entrevistados defendem que é importante estar nas plataformas. No entanto, estando lá, também é difícil gerir. Cada vez é mais complicado identificar o público consumidor. A vantagem de estar associado ao agregador pode traduzir-se em desvantagem. É verdade que o agregador

2. Tradução de: Information motivations: to find out what's going on in the world; entertainment motivations: it's a habit, is exciting and when there is nothing better to do; social motivations: to keep up what other people around you may be talking about, to feel a part of community and have something to talk with others; opinion motivations: to help you to form opinions on issues and to expose yourself to views that are different from your own" (p.12). 
potencia uma maior visibilidade e consegue chegar a novos públicos, mas estas vantagens podem transformar-se numa dependência extrema face aos agregadores, despoletando uma falta de reconhecimento e um desbaratamento da marca dos media.

Para concluir esta categoria, os entrevistados comprovaram que os agregadores dão mais visibilidade do que propriamente "tiram" audiência, embora essa visibilidade seja relativa. As pessoas consomem sempre em detrimento de alguma coisa, o que não implica que se deixe de consumir televisão porque estou a consumir o Sapo. O estudo de Lee e Chyi comprova isso mesmo: "contrariamente à expectativa, aqueles que consomem notícias dos agregadores são, na sua grande maioria, os leitores que também consomem notícias de outros media" (2015:18 tradução nossa) ${ }^{3}$. Isto comprova que a pessoa pode consumir simultaneamente um agregador e um media tradicional. Por sua vez, também pode consumir um meio em detrimento de outro, mas esse comportamento não é determinado pelos agregadores, mas sim por questões culturais e ideológicas.

3. Tradução de: "contrary to expectation, those who consume news from news aggregators are, in most cases, more likely to also consume news from other news media outlets, other things being equal" (2015:8). 
Jornalismo 3.0: o impacto dos agregadores de notícias online no negócio da informação

Tabela 3. A perceção dos stakeholders face ao modelo de negócio

\begin{tabular}{|c|c|}
\hline Posição favorável & Posição desfavorável \\
\hline Otimização e monetização dos conteúdos & Falta de acompanhamento da estrutura de custos \\
\hline $\begin{array}{l}\text { Maior alcance e reforço do posicionamento das } \\
\text { marcas }\end{array}$ & $\begin{array}{l}\text { Empresas tecnológicas assumem-se como empre- } \\
\text { sas de media }\end{array}$ \\
\hline Os agregadores são um incremento adicional & Dificuldade em viver "fora da caixa" \\
\hline Receita partilhada entre agregadores e os media & $\begin{array}{l}\text { Quebra de receitas não foi compensada pelo digi- } \\
\text { tal }\end{array}$ \\
\hline $\begin{array}{l}\text { Adaptação dos parceiros à linha editorial dos agre- } \\
\text { gadores }\end{array}$ & Falta de adequação do modelo low pay \\
\hline Rentabilização dos conteúdos & $\begin{array}{l}\text { Medo, atraso e desconfiança não se coaduna com } \\
\text { o modelo de negócio }\end{array}$ \\
\hline $\begin{array}{l}\text { Captação de novas receitas com o aumento de pla- } \\
\text { taformas da mesma marca }\end{array}$ & Dependência dos agregadores como sales house \\
\hline Parcerias e fortalecimento das relações & Analisar o futuro com base nos "old media" \\
\hline Chegar a outros públicos & $\begin{array}{l}\text { Não houve uma passagem total da publicidade do } \\
\text { tradicional para o mobile }\end{array}$ \\
\hline \multirow[t]{5}{*}{ Organização da informação } & Inovação disruptiva leva à falta de investimento \\
\hline & Pulverização da marca \\
\hline & Forte concorrência face aos players internacionais \\
\hline & Baixa receita gerada pelos agregadores \\
\hline & Falta de maturidade face aos agregadores \\
\hline \multicolumn{2}{|c|}{ Desafios/Possíveis problemas } \\
\hline Evolução dos modelos de negócio & $\begin{array}{l}\text { Não deixar que a potenciação dos agregadores de- } \\
\text { sequilibre o medium }\end{array}$ \\
\hline $\begin{array}{l}\text { Procurar um modelo de negócio viável e favorável } \\
\text { entre ambos }\end{array}$ & $\begin{array}{l}\text { Pensar nos agregadores como uma vertente finan- } \\
\text { ceira }\end{array}$ \\
\hline Mostrar valor e saber vender a marca & Diferenciação do produto \\
\hline
\end{tabular}

A terceira categoria trata o modelo de negócio presente nos media tradicionais e nos agregadores de notícias, bem como com as reestruturações e impactos que se verificam no negócio com a entrada de novos agentes (tabela 3). A atual crise económica levou a uma queda abrupta da receita e a uma falta de acompanhamento da estrutura de custos. Com a passagem do tradicional para o digital, a quebra de receitas publicitárias não foi compensada pela publicidade via digital. O retorno que os meios estão a ter está muito aquém do que era esperado. A repartição do espaço publicitário pelos vários players num mercado em crise e extremamente concorrente, também tem vindo a prejudicar as receitas e o investimento dos restantes media. A inovação disruptiva também leva à falta de investimento. Grande parte da publicidade e da audiência está a migrar para os media sociais, pelo que se verifica uma desigualdade de acesso ao investimento em relação aos restantes media.

O facto de os agregadores pertencerem a grandes conglomerados como a Microsoft ou a Google, por exemplo, dá-lhes a vantagem de conseguirem fazer uma integração multissectorial de 
várias áreas. Oferecem marcas e informação dos media numa única plataforma, aliando inovação, tecnologia e investimento, o que os media tradicionais não conseguem oferecer no seu conjunto. Portanto, são novas empresas de media com novos modelos de negócio que estão em vantagem face aos restantes media, pois aliam inovação, tecnologia e informação.

"O verdadeiro desafio é estar num mercado que cresce muito, onde esse crescimento foge para os grandes players internacionais, com os nacionais a ficarem com tão pouco. Nunca conseguiríamos competir com o Facebook ou o Google na área deles, por isso vamos nós procurar e desenvolver melhor as nossas áreas. Se oferecer um produto diferente terei mais sucesso. Os publishers têm de ter a capacidade de mostrar o nosso valor e saber vender-nos." (Diretor do Observador, media híbrido - grupo dos media tradicionais).

O modelo de negócio dos agregadores assenta numa política de revenue share, ou seja, são estabelecidas percentagens de receita partilhada entre media e agregadores. Outro tipo de parceria são as Sales House. O Sapo optou por esta forma de negócio, em que é responsável por vender a publicidade do media, e em troca o media tem de lhe fornecer os seus conteúdos e dar-lhe o domínio do seu site. Por exemplo, a Rádio Renascença já faz isso: cada vez que acedemos ao site deles, a URL aparece da seguinte forma: http://rr.sapo.pt/. Ou seja, o Sapo detém o domínio da Rádio Renascença.

Como referido anteriormente, o receio e a falta de controlo dos media sobre os seus conteúdos levou a que alguns media restringissem o uso diário de notícias no agregador. Por exemplo, no contrato de parceria entre o agregador MSN e o jornal Público, este disponibilizava apenas quinze peças de conteúdo por mês, pelo que a baixa receita que obtinha não compensava, o que acabou por levar ao rompimento do contrato com o agregador. É muito difícil rentabilizar e conseguir lucro quando o parceiro restringe a sua oferta. $\mathrm{O}$ facto de o grupo Impresa ter rompido o contrato com o Sapo deveu-se sobretudo ao medo e à desconfiança de ficar totalmente dependente de um agregador para conseguir obter receita.

Outros caso importante de referenciar é o do grupo Global Media, que mais recentemente criou um site chamado Delas, que se adequa muito ao tipo de oferta dada pelos agregadores, ou seja, é um site que oferece um leque variado de conteúdos ligados mais às soft news e ao entretenimento. Começa a ver-se a necessidade de alguns media se moldarem às exigências e ao tipo de público de um agregador, adequando a sua oferta ao agregador em simultâneo com o panorama de consumo noticioso em geral.

Os media híbridos, no que respeita ao modelo de negócio, apostam na diversificação de plataformas dentro da mesma marca, fomentando a ideia de incremento de receita sem dependência dos agregadores e dos media sociais. É uma forma de não depender economicamente e também de a audiência não migrar para outras plataformas. O objetivo do media híbrido é dar variedade de escolha e disponibilizar o máximo de conteúdo possível nas suas plataformas, como se fossem agregadores.

"Pretende-se captar novas receitas publicitárias e, além disso, conseguirmos ir até onde estão os leitores. E se os leitores estão no digital, é lá que se deve estar para os procurar. Além disso, detetámos que em Portugal não existe atualmente nenhum jornal vespertino e a ideia do Expresso Diário, que sai pelas 18h00, é que seja não só um digest do dia, mas ao mesmo 
tempo uma forma de tentarmos antecipar o que se vai passar no dia seguinte e o que os restantes jornais diários em papel vão trazer na manhã seguinte.” (Expresso, media híbridos grupo dos media tradicionais).

No caso dos media sociais, a partilha de receita só se faz pela publicidade e não pelos conteúdos. O próprio Facebook já se considera um media, na medida em que alberga conteúdo, tem tráfego e publicidade, portanto aquilo que qualquer media tem. Segundo alguns entrevistados, os agregadores têm de ser vistos como um incremento adicional de receita, já que trazem maior alcance e melhoram o posicionamento da marca. O grande problema é o facto de os media ainda viverem na sombra do receio face aos agregadores, e terem dificuldade de "viver fora da caixa", analisando o futuro sempre com base nos media tradicionais.

Em suma, nesta categoria, os media devem procurar diversificar os seus produtos, estabelecer mais sinergias e pensar nos agregadores como uma vertente financeira, não deixando que essa potenciação dos agregadores desequilibre os media. Os modelos de negócio estão em constante evolução, daí a necessidade de encontrar um modelo viável e favorável para ambos (Cagé, 2016). 
Tabela 4. A perceção dos stakeholders sobre a relação entre os media

\begin{tabular}{|c|c|}
\hline Posição favorável & Posição desfavorável \\
\hline Competição direta de igual para igual & $\begin{array}{l}\text { Os agregadores são vistos como uma ameaça, vi- } \\
\text { vem do negócio dos outros }\end{array}$ \\
\hline Não há canibalização do negócio & $\begin{array}{l}\text { Vazio de um modelo de negócio entre agregadores } \\
\text { e parceiros de media }\end{array}$ \\
\hline Os agregadores são curadores de conteúdo & Roubo de direitos aos media \\
\hline $\begin{array}{l}\text { Relação de co-petição (cooperação, mutualismo e } \\
\text { competição) }\end{array}$ & $\begin{array}{l}\text { Falta de atenção e atraso dos media face às empre- } \\
\text { sas tecnológicas }\end{array}$ \\
\hline $\begin{array}{l}\text { Os produtores não competem com distribuidores } \\
\text { de conteúdo }\end{array}$ & Divisão desigualitária da receita \\
\hline $\begin{array}{l}\text { Concorrência está no investimento, na publicidade } \\
\text { e não nas notícias }\end{array}$ & O Google como um negócio parasitário \\
\hline Uniformização da plataforma no Facebook & $\begin{array}{l}\text { Consumo de media em detrimento de outros me- } \\
\text { dia }\end{array}$ \\
\hline $\begin{array}{l}\text { Agregadores não roubam audiência, é um presta- } \\
\text { dor de serviços }\end{array}$ & Dependência face aos agregadores \\
\hline Relação de parceria versus ódio & Visibilidade limitada \\
\hline \multicolumn{2}{|l|}{$\begin{array}{l}\text { Captar público para a nossa marca e não através } \\
\text { de outras }\end{array}$} \\
\hline \multicolumn{2}{|l|}{ Competição vertical mais do que horizontal } \\
\hline \multicolumn{2}{|c|}{ Desafios/Possíveis problemas } \\
\hline $\begin{array}{l}\text { Adaptação dos media à nova realidade senão fi- } \\
\text { cam para trás }\end{array}$ & $\begin{array}{l}\text { O facto de o Facebook ter uma web própria de no- } \\
\text { tícias constituí uma ameaça ao jornalismo }\end{array}$ \\
\hline $\begin{array}{l}\text { Ajustar as formas de veicular as notícias para não } \\
\text { perder leitores }\end{array}$ & $\begin{array}{l}\text { Mudança de culturas pode reestruturar modelos e } \\
\text { relações de negócio }\end{array}$ \\
\hline Movimentos de convergência de vários grupos & $\begin{array}{l}\text { Multiplicação dos produtores independentes, dos } \\
\text { pequenos produtores }\end{array}$ \\
\hline $\begin{array}{l}\text { Maior abertura de negócio entre os media e os } \\
\text { agregadores }\end{array}$ & $\begin{array}{l}\text { Facebook como uma ameaça para o próprio Goo- } \\
\text { gle }\end{array}$ \\
\hline $\begin{array}{l}\text { Guerra "titânica" entre Google e Facebook, tudo } \\
\text { gira em volta deles }\end{array}$ & \\
\hline
\end{tabular}

A última categoria de análise trata a relação entre os media e os agregadores de notícias (tabela 4). Em linhas gerais, a relação entre ambos permanece ainda confusa, é uma relação de amoródio, na medida em que os agregadores podem constituir uma vantagem e ao mesmo tempo uma desvantagem para os media.

Todos competem pelo mesmo bolo, a competição é mundial, não é binária, ou seja, é uma competição mais vertical do que horizontal. Os produtores de media não devem competir diretamente com os distribuidores. É uma relação conturbada, porque embora os agregadores deem visibilidade, os media têm medo porque não querem ser eles a estimular a fragmentação do seu próprio conteúdo e a pô-lo disponível em todo o lado. 
"Estar associado aos agregadores pode levar à pulverização da marca, à indiferenciação da origem do conteúdo. O problema aqui é a falta de domínio da plataforma de distribuição. As marcas de media têm dificuldade em "viver fora da caixa"; a vantagem acaba por tornar-se ao mesmo tempo a desvantagem;" (Grupo media tradicionais).

Os agregadores competem em termos de audiências com outros agregadores. Por seu turno, todos os media e agregadores competem uns contra os outros em termos de investimento. A concorrência está na publicidade e no investimento, e não nas notícias.

O agregador sempre foi visto por muitos como uma ameaça e é acusado de viver do negócio dos outros, ou seja, é considerado um negócio parasitário. No entanto, ficou provado neste estudo que não existe canibalização do negócio. É tudo feito através de um processo legal de revenue share, garantindo todos os direitos de copyright aos produtores dos conteúdos. O agregador é como um prestador de serviços. Os autores Lee e Chyi (2015) vieram comprovar no seu estudo que não existe uma competição direta entre agregadores e os media tradicionais, e que não existe "roubo" de conteúdo e de receita quando se trata de um processo legal assinado por ambas as partes.

No entanto, existem ainda alguns entrevistados que afirmam que os agregadores tiram partido do investimento dos media para fazerem o seu negócio, já que precisam das notícias para garantir a sobrevivência online dos agregadores. Segundo o grupo dos media tradicionais, fazer notícias implica gasto de recursos, logo os agregadores tiram também partido desses recursos e investimento usado por parte dos produtores (Grupo dos media tradicionais).

"O agregador funciona como um alerta de notícias, anuncia. Quando quero ver notícias mais detalhadas vou a meios mais específicos. A visibilidade é limitada, há uma situação de roubo de direitos a quem gastou dinheiro a produzir aquela notícia." (Jornalista sénior e professor, grupo dos media tradicionais).

Alguns entrevistados referem que os agregadores não são produtores de conteúdos, são curadores, não constituindo qualquer tipo de ameaça. O agregador é equiparado a um prestador de serviços. E dessa forma os produtores de conteúdo não competem diretamente com os distribuidores de conteúdo, pois a competição não é direta nem de igual para igual. No fundo os agregadores "roubam", mas de forma legal e consentida. "A competição é mundial, internacional e não apenas de agregadores para agregadores ou de tradicionais para tradicionais. Todos competem no mesmo bolo." (João Galveias, diretor da RTP). Por outro lado, alguns entrevistados referem que os agregadores vivem do negócio e dos conteúdos dos produtores, e que o Google News é um parasita.

Para o grupo dos agregadores, deve haver uma relação de "co-petição", ou seja, uma relação de cooperação e de competição saudáveis, construindo sinergias e relações institucionais vantajosas para ambos. Ou seja, tentar perceber de que forma me posso adaptar à nova realidade e fixar um posicionamento para garantir a competitividade do mercado.

É também importante salientar que o Google não vê o Facebook como um inimigo, na medida em que se complementam. O Google não perde relevância porque se foi ao Facebook, as pessoas nunca vieram ao Google com a expectativa de encontrar o que encontram no Facebook e não deixam de usar o Google para fazer as suas pesquisas. 
Em suma, adaptar-se às novas realidades parece ser inevitável para os media tradicionais, caso contrário correm o risco de serem ultrapassados por novas formas de produção e distribuição de informação. Os media não podem ignorar a vertente financeira dos agregadores, e deixar que a relevância dos agregadores os desequilibre. As mudanças culturais e comerciais reestruturam os modelos e as relações de negócio que estão em constante evolução. Atualmente, os media vivem num mercado onde se assiste a uma competição cada vez mais intensa entre os gigantes da tecnologia - o Google e o Facebook. Estes detêm a maior fatia de receitas do consumo de informação e as empresas de media vêm o retorno desse consumo como quase residual quando comparado com os dividendos destes novos players.

\section{CONCLUSÃo}

Este artigo teve como principal objetivo debater o impacto dos agregadores de notícias online no jornalismo em Portugal, no que respeita à audiência e às mudanças na produção e gestão noticiosa a partir da perspetiva dos players do negócio. Para tal, centrámo-nos em dois grandes grupos de stakeholders: o grupo dos agregadores de notícias - formado por editores, diretores, grupos de media portugueses, media sociais e meios híbridos - e o grupo dos media tradicionais formado por jornalistas e diretores. Tendo em conta os principais protagonistas, centrámo-nos em quatro categorias fundamentais no negócio da informação: produção noticiosa, audiência, modelo de negócio e relação entre os media. Estes eixos de análise permitiram-nos extrair as perceções dos envolvidos com respeito às mudanças em curso no mercado da informação.

Por ser um estudo pioneiro em Portugal, implicou a construção de um projeto de trabalho específico para conseguir obter dados de reflexão sobre a questão em análise. A partir de uma metodologia qualitativa, desenvolvemos uma investigação de natureza exploratória. $\mathrm{O}$ facto de não haver uma base de estudos sobre os agregadores em Portugal constituiu um enorme desafio, não isento de riscos. Centrámo-nos então na perspetiva dos atores envolvidos diretamente nas mudanças em curso no negócio da informação. Deste modo, as conclusões extraídas neste artigo tiveram por base as entrevistas realizadas, ou seja, as perceções dos vários players no negócio da informação.

Dessa forma, a primeira linha de análise tratou de investigar os principais desafios e mudanças na produção jornalística na atividade noticiosa. Conclui-se que os agregadores de notícias vieram ampliar, agregar e distribuir melhor a informação. Os agregadores condensam tudo na mesma plataforma, oferecendo aquilo que os utilizadores querem consumir, melhorando assim a distribuição das notícias. Cada vez mais, a afirmação da notícia está dependente da audiência. Verifica-se a passagem do valor-notícia para o valor-audiência, em que aquilo que é noticiável está muito ligado ao interesse do público e não naquilo que o público precisa saber. As prioridades da agenda dos media e o que define notícia está muito aquém do que era antigamente. No entanto, isso não significa que tenham sido os agregadores de notícias os responsáveis pela alteração do conceito de notícia. Segundo a grande maioria dos entrevistados, os agregadores vieram alterar a forma de distribuição das notícias e não o seu conteúdo. Esse sim foi alterado por imposições culturais, comerciais e sociais. A democratização do acesso e a viragem dos interesses dos media para a cultura popular fomentou a afirmação do cidadão comum. Deixa de haver o produtor específico e 
especializado. Qualquer pessoa, hoje, pode produzir conteúdo e simultaneamente consumir sem ter de esperar. Estes efeitos traduzem-se numa banalização da profissão do jornalista, que passa a ser cada vez mais um curador de conteúdo. O Expresso, um meio híbrido, criou mais recentemente outras plataformas de distribuição e promoção do seu conteúdo. É uma forma de contrariar e moderar o uso de agregadores, desmultiplicando e condensando em plataformas a informação. No fundo, o Expresso comporta-se como um agregador, mas do seu próprio conteúdo.

A segunda linha de análise centrou-se nas transformações nos padrões de consumo devido aos agregadores. Conclui-se que quem consome agregadores está englobado num público "apanhado na rede", passivo e menos exigente. Na maioria das vezes, não vão em busca de notícias, acabando por ficar no agregador. Esta investigação permitiu identificar os fatores pelos quais as pessoas mais consomem. O utilizador consome tanto agregadores como outros media porque se quer sentir informado, isto é, cumprir o seu dever de cidadão informado, saber o que se passa no mundo. E também por motivações de entretenimento e sociais. A internet tornou-se hoje um armazenador de webs e plataformas fomentando a fragmentação das audiências, que já não se concentram em apenas um lugar, mas em vários. O consumo é cada vez mais descentralizado e fragmentado, pelo que se torna difícil chegar a outros públicos. Daí que uma das vantagens que os entrevistados destacaram foi a possibilidade de os agregadores conseguirem chegar a outros públicos e dar mais visibilidade aos media, quando a atenção é cada vez mais repartida.

Existe competição entre os media, sobretudo pelo tempo disponível na rotina de consumo digital do utilizador. No entanto, os media produtores não competem diretamente com distribuidores de conteúdo. Outro aspeto a concluir é que as pessoas que consomem agregadores também consomem meios tradicionais, ou seja, não deixam de consumir meios em detrimento de outros.

A última subquestão tratou de investigar qual é a relação existente entre os media tradicionais e os novos meios de comunicação online. Conclui-se que caracterizar assertivamente a relação entre os media é difícil, quando nos referimos a uma relação ainda confusa e recente. Embora os agregadores já estejam presentes no mercado há alguns anos, os media só passaram a incluílos e a conferir-lhes importância recentemente. É uma relação ainda muito na base do medo, do receio e do atraso face aos agregadores. Isto acontece porque os media ainda não aceitaram que os agregadores potenciam a sua marca, não se apropriam dela. No que respeita ao mercado das notícias, em termos de negócio, existe hoje um problema ainda maior. $\mathrm{O}$ facto de o investimento estar a fugir para os media sociais gera uma repartição desigual dos lucros. $\mathrm{O}$ medo, o atraso e a desconfiança fazem com que os meios tradicionais não avancem a 100\% para os agregadores. Daí que muitos entrevistados, principalmente do grupo dos agregadores de notícias, considerem que os agregadores e os media se devem aliar contra o modelo de negócio praticado pelos media sociais, de forma a tentarem recuperar o investimento. Uma forma de evitar a dependência de agregadores e de media sociais é dada pelo caso do Expresso, como referido anteriormente. As relações entre os media influenciam o negócio e um novo modelo financeiramente viável ainda está por definir. O agregador compete pelo tempo do utilizador no consumo do digital, pelo que não implica o abandono da missão jornalística de investigar e publicar informação relevante no quadro de uma sociedade democrática. O jornalismo está a passar por uma fase de grande mudança e procura $\mathrm{o}$ seu lugar no contexto digital. 
Em suma, este artigo procurou conhecer como é que os vários stakeholders envolvidos estão a perspetivar as mudanças em curso. Cada parte tem um olhar específico sobre a questão, ou seja, o que é entendido como uma vantagem para um dos lados, pode ser olhado como um problema para qualquer das outras partes. A tensão e o conflito entre os diferentes protagonistas do setor dos media sempre fizeram parte do negócio da informação e as transformações tecnológicas em curso, para além de introduzirem novidades, vieram colocar ainda mais no centro do debate em torno do jornalismo velhas questões ligadas à viabilidade do modelo de negócio.

Evidencia-se assim um paradoxo: por um lado, os agregadores constituem uma vantagem pela visibilidade e angariação de novos públicos, mas, por outro lado, a sua dependência é sentida como uma ameaça, isto porque o meio de comunicação já não consegue sobreviver sem o agregador, acabando por se perder a valorização da própria marca. De modo simplificado, poderemos dizer que o que os salva é um pouco aquilo que os "mata". O mercado dos media está sempre em constante transformação, porventura daqui a uns anos poderão ser os agregadores a terem de se adaptar a outras tendências emergentes, já que estão paulatinamente a perder o seu papel para os media sociais.

\section{REFERÊNCIAS BIBLIOGRÁFICAS}

Athley, S. \& Mobius, M. (2012). The Impact of News Aggregators on Internet News Consumption: The Case of Localization.

Bakker, P. (2012). New journalism 3.0: Aggregation, Content farms and Huffinization: the rise of low-pay and no-pay Journalism. Hogeschool Utrecht: University of Amsterdam.

Bardin, L. (1977). Análise de Conteúdo (trad. L. A. Reta \& A. P. Capa). Lisboa: Edições 70.

Bolt, J. \& Grusin, R. (1999). Remediation: understanding the new media. University of United States of America.

Cagé, J. (2016). Salvar os Média. Lisboa: Temas e Debates - Círculo de Leitores.

Cardoso, G. et al (2015). A sociedade em rede em Portugal - Uma Década de Transição. Coimbra: Almedina.

Creswell, J. (2007). Projeto de pesquisa: métodos quantitativos, qualitativos e misto. São Paulo: ARTMED.

Deuze, M. (2006). Liquid Journalism. Indiana: USA.

Deuze, M. (2007). Liquid Journalism. Disponível em http://deuze.blogspot.pt/2007/05/moreliquid-journalism.html. Consultado a 28-02-2016.

Deuze, M. (2008). The Changing Context of News Work: Liquid Journalism and Monitorial Citizenship.

ERC (2015). Digital Media Portugal. Disponível em www.erc.pt/download/YToyOntzOjg6ImZpY 2hlaXJvIjtzOjM4OiJtZWRpYS9lc3R1ZG9zL29iamVjdG9fb2ZmbGluZS83OS4xLnBkZiI7 czo2OiJ0aXR1bG8iO3M6Mjc6ImRpZ210YWwtbWVkaWEtcG9ydHVnYWwtMjAxNSI7f $\mathrm{Q}==/$ digital-media-portugal-2015. Consultado a 15-01-2016. 
Fenton, N. (2010). New Media, Journalism and Democracy: Figments of a Neo- Liberal Imagination?. Revista Media \& Jornalismo, (17): 41-52. Lisboa: Edição Mariposa Azual.

Foust, J. C. (2005). Online Journalism: principles and practices of news for the web. Holcomb Hathaway: USA.

Guerrini, F. (2013). Newsrom curators \& Independent Storytellers: Content Curation as a New Form of Journalism. Reuters Institute for the Study of Journalism: University of Oxford.

Google (s.d.). Notícias. Disponível em https://news.google.pt/. Consultado em 02-12-2015.

Holton, A.E. (2010). Negating Nodes and Fifth-Stage Fragmentation. New applications of traditional communication models and theories in the midst of diffusing communication innovations. New Media Theory: How far Have We Traveled? (pp. 1-27). Texas Tech University, College of Mass Communications.

Homepage do Sapo.pt (s.d.). Disponível em www.sapo.pt/. Consultado a 01-12-2015.

Jenkins et al. (2013). Spreadable media: creating value and meaning in a networked culture. New York: University Press.

Lee, A. M. \& Chyi, H. I. (2015). The Rise of online news aggregators: consumption and competition. International Journal on Media Management.

Lee, A. M. \& Chyi, H. I. (2012). Theorizing Online News Consumption: A Structural Model Linking Preference, Use, and Paying Intent. Paper presented at the 13th International Symposium on Online Journalism, Austin, TX, April 20-21, 2012.

Lopes, F. (2015). Jornalista: Profissão Ameaçada. Lisboa: Alêtheia Editores.

Maxwell, J. (2005). Qualitative Research Design: an interactive approach. Thousand Oaks; London; New Delhi: Sage.

MSN notícias Portugal (s.d.). Disponível em www.msn.com/pt-pt. Consultado a 02-12-2015.

Patterson, C. \& Domingo, D. (2008). Making online news. New York: Peter Lang.

Prior, M. (2005). News vs. Entertainment: How increasing media choice widens gaps in political knowledge and turnout. American Journal of Political Science, 49(3).

PucRio (s.d.). Metodologia de Maxwell. Disponível em www.maxwell.vrac.puc-rio.br/9443/9443 _4.PDF. Consultado a 17-04-2016.

Turner, G. (2010). Ordinary People: celebrity, tabloid culture, and the function of the media. Ordinary People and the Media: The Demotic Turn (pp. 12-32). London: Sage.

Usher, N. (2014). Making News at the New York Times. Ann Arbor: The University of Michigan Press. 